Universidad de Lima

Facultad de Comunicación

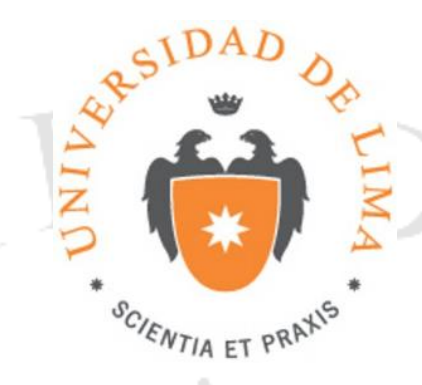

\title{
FICCIONALIZACIÓN DE LAS EXPERIENCIAS SEXUALES. EL DISCURSO DE LOS USUARIOS DE FOROS DE INTERNET SOBRE KINESIÓLOGAS
}

Trabajo de investigación para optar el Título Profesional de Licenciado en Comunicación

\author{
Diego Alejandro Romero Ramirez \\ Código 20111098
}

\author{
Asesora \\ Lilian Kanashiro Nakahodo
}

Lima - Perú

Junio del 2017 


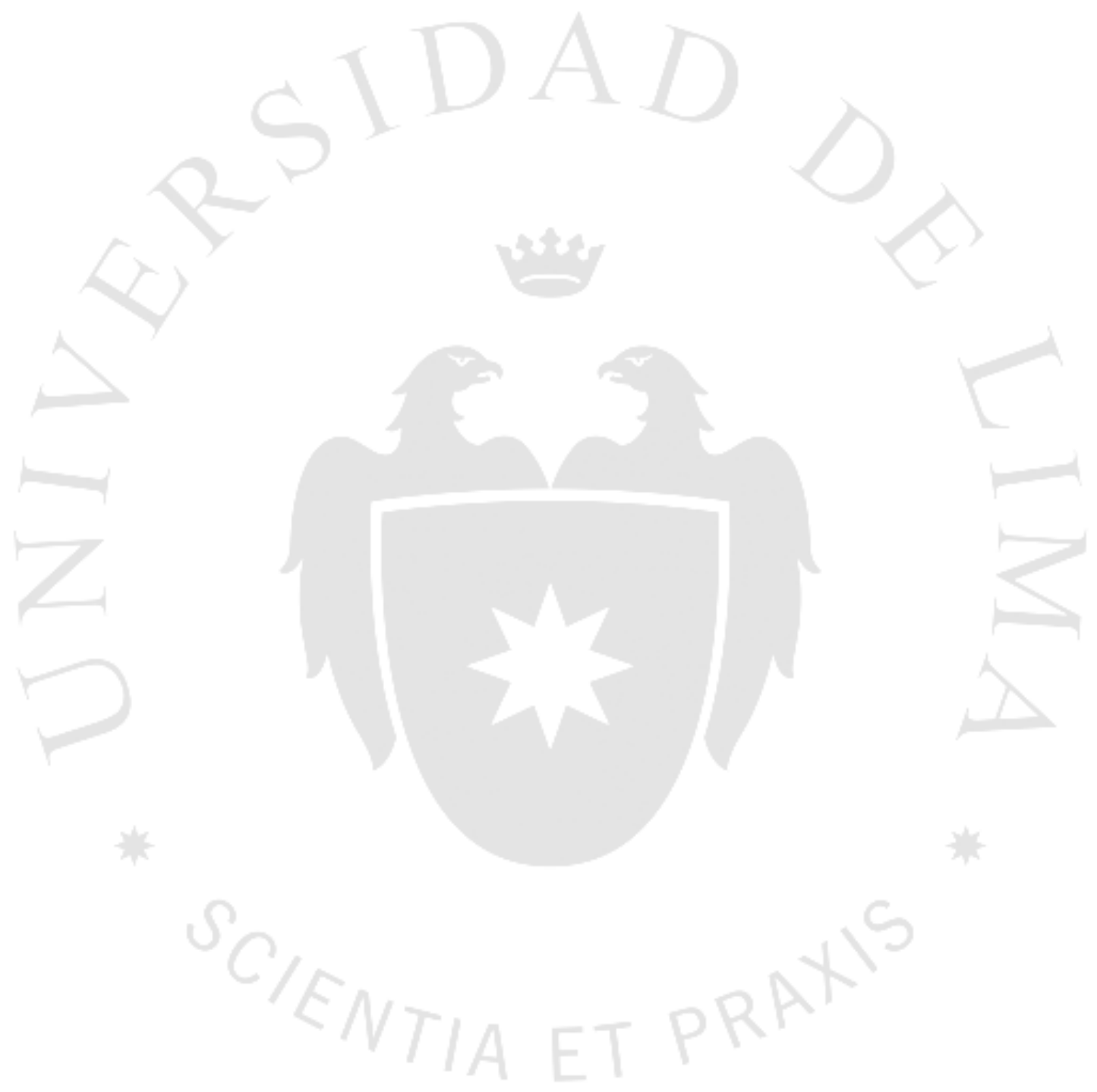




\section{FICCIONALIZACIÓN DE LAS EXPERIENCIAS SEXUALES. EL DISCURSO DE LOS USUARIOS DE FOROS DE INTERNET SOBRE KINESIÓLOGAS}




\section{Resumen}

Una de las consecuencias del vertiginoso avance tecnológico de los últimos años ha sido la alteración de uno de los pilares de la cotidianeidad del ser humano: la sexualidad. Así, las tradicionales prácticas sexuales adquirieron nuevas posibilidades y escenarios para su desenvolvimiento. Este panorama, a su vez, brindó a los académicos nuevos puntos de vista desde los cuales aproximarse a este campo de estudio. Es así que este artículo analizó las características del discurso de los usuarios que forman parte del foro peruano ZonaCaleta, espacio virtual dedicado al intercambio de información sobre encuentros sexuales con prostitutas. Para ello se tomó como muestra 100 posts publicados en el 2015, los cuales fueron examinados a través de tres matrices: la primera buscó particularidades lingüísticas en el discurso, la segunda identificó algunas dinámicas tensivas que determinaban las sensaciones de placer o displacer en los foristas, y la tercera se ocupó de analizar la plataforma en sí. Gracias a estas herramientas se arribó hacia conclusiones tales como la existencia de un sociolecto entre los usuarios, la ficcionalización de los relatos a partir del uso de elementos literarios o la marcada cosificación del cuerpo femenino presente en el discurso de los foristas.

Palabras clave: Prostitución - Semiótica - Foros - Sexo - Relatos eróticos - Comunidad virtual

\section{Abstract}

One of the consequences of the vertiginous technological advance of the last years has been the alteration of one of the pillars of the daily life of the human being: sexuality. Thus, the traditional sexual practices acquired new possibilities and scenarios for their development. This panorama, in turn, provided the academics new points of view to approach to this field of study. Therefore, this article analyzed the characteristics of the speech of the users that form part of the peruvian forum ZonaCaleta, virtual space dedicated to the exchange of information on sexual encounters with prostitutes. In order to do that, 100 posts published in 2015 were taken as sample and they were examined through three matrices: the first one searched for linguistic peculiarities in the discourse, the second identified some tensive dynamics that determined the feelings of pleasure or displeasure the forum members felt, and the third analyzed the platform itself. Thanks to these tools, we arrived at some important conclusions such as the existence of a sociolect among the users, the fictionalization of the stories due to the use of literary elements or the marked reification of the female body present in the discourse of the forum members.

Keywords: Prostitution - Semiotics - Forums - Sex - Erotic stories - Virtual Communities 


\section{Introducción}

El advenimiento de internet ha transformado diversos ámbitos de la vida social y cultural de las personas. Uno de los aspectos que más cambios ha experimentado al encontrar un nuevo soporte donde desarrollarse es la sexualidad. Las diversas prácticas sexuales han desarrollado nuevas formas de expresión y desenvolvimiento en el mundo online que están impulsando numerosas investigaciones para comprender sus características y efectos.

En ese sentido, este trabajo ha tomado como objeto de estudio el foro peruano ZonaCaleta, espacio virtual en el que diversos usuarios narran sus experiencias sexuales con meretrices. Y, más específicamente, la investigación busca echar luces sobre la siguiente interrogante: ¿Cuáles son y qué caracteriza a las nuevas formas discursivas en torno a la sexualidad representada en soportes digitales?

En aras de dilucidar esta problemática, se plantea como objetivo principal analizar las características del discurso de los individuos que participan activamente en el foro ZonaCaleta. Para ello, es necesario abordar el tema a partir de tres objetivos específicos. En primer lugar, describir las particularidades lingüísticas presentes en las intervenciones de los foristas. En segundo lugar, identificar algunas de las dinámicas tensivas que determinan la experiencia de placer o displacer en sus encuentros sexuales. Y, finalmente, analizar la plataforma que los alberga empleando el modelo sociosemiótico elaborado por Carlos Scolari.

\section{Acerca de la sobreexposición de la vida privada en el espacio público}

Un rasgo característico de la sociedad contemporánea es la paulatina evanescencia de la línea que separa la esfera pública de la privada. Así, a través de la constatación del cambio de diversas prácticas culturales, muchos autores han señalado que existe un trastocamiento del concepto de intimidad. Precisamente, la argentina Paula Sibilia es una de las que más ha investigado y teorizado sobre este tema en los últimos años. 
Sibilia (2008) enmienda de plano una creencia bastante difundida en el campo científico acerca de la superposición existente entre la esfera privada y la pública. Para ella, la supuesta separación conceptual que siempre hubo entre estos ámbitos y que, en teoría, se estaría perdiendo no es más que una invención histórica y una convención cultural. Ello debido a que la noción de una esfera privada se popularizó recién en los siglos XVIII y XIX como consecuencia del surgimiento de un nuevo modo de vida urbano en Europa producto de la industrialización. Por ende, el espacio privado se habría configurado como una suerte de refugio frente a las vicisitudes del espacio público.

En esa línea, el semiólogo francés Eric Landowski añade que esta separación conceptual tampoco es tan taxativa y recomienda "descartar la idea, ampliamente admitida pero errónea dado que es muy restrictiva en sus efectos, según la cual lo 'privado' podría ser asimilado a lo individual (y correlativamente, lo 'público' a lo colectivo)" (Landowski, 1993, p. 115). Así, Landowski (1993) afirma que existe dentro de la individualidad un componente privado y uno público. El primero hace referencia al espacio más intimo del yo como, por ejemplo, escribir en un diario personal, mientras que el segundo se refiere a un yo socializado en tanto el individuo tiene una consciencia influida por el entorno social en el que vive, es decir, una consciencia del nosotros. De igual manera, existe también dentro de la colectividad un componente privado y uno público. El primero se distingue por englobar prácticas comunicativas de rasgos interiores como debates, reuniones o conversaciones a puertas cerradas, y el segundo por requerir necesariamente una audiencia o público para la emisión de su discurso como una conferencia de prensa, un concierto o un performance artístico.

Ahora bien, a pesar de señalar que la separación público/privada es un construscto histórico y cultural, Sibilia (2008) no niega que los factores que llevaron a la escisión entre estos ámbitos estén en plena transformación y que eso derive en una sobreexposición de la vida íntima. La autora enfatiza que estas ansias por exponer la intimidad a los ojos del mundo se deben a un cambio en la configuración de la subjetividad de las personas, que a su vez es ocasionado por una transformación en la cultura que habitan. Este nuevo ámbito cultural esta signado por la espectacularización, que invade todos los ámbitos de nuestra 
cotidianeidad: nuestra manera de vivir, de relacionarnos e interactuar con los demás, la forma como percibimos el mundo y el modo como se estructura la realidad.

Es esta sociedad del espectáculo la que demanda de sus habitantes la exposición de la intimidad a través de las diversas pantallas que hoy existen, de modo que los individuos terminan por convertir sus propias vidas en un show mediático. En ese sentido, el filósofo esloveno Slavoj Zizek (2005) sostiene que:

La verdad última del repliegue en la privacidad es una confesión pública de los secretos íntimos en un espectáculo televisivo, frente a este tipo de privacidad deberíamos enfatizar que en la actualidad la única forma de romper con los imperativos de la mercantilización «alienada» es inventar una nueva colectividad. (p. 70).

Sibilia también recalca que el incremento de las prácticas 'confesionales' que inundan el mundo virtual se apoya en el desarrollo y la practicidad de los aplicativos digitales que provee la web a sus usuarios. Así, "las nuevas herramientas permiten registrar todo tipo de escenas de la vida privada con facilidad, rapidez y bajo costo, además de inaugurar nuevos géneros de expresión y canales de divulgación” (Sibilia, 2008, p. 289).

Los blogs, foros, fotoblogs y streamings son solo algunos espacios donde se expone la vida privada de las personas, quienes no solo desean exhibirla sino también consumir la de otros. Por ello, Sibilia (2008) señala que cada individuo se convierte en el protagonista de sus vivencias, expuestas a nivel global y decoradas con recursos mediáticos en busca de hacer más real lo real. De esta manera se configura una necesaria ficcionalización de la realidad pues son estos relatos los que nos moldean como sujetos.

Por su parte, Charles Baudrillard (2000) advierte que uno de los efectos provocados por esta recreación del yo a nivel virtual es la pérdida de identidad: 
[El] hecho de que la identidad sea la de la red y nunca la de los individuos, el hecho de que la prioridad se dé a la red más que a los protagonistas de la red, conlleva la posibilidad de disimularse en ella, de desaparecer en el espacio impalpable de lo virtual y no estar ya localizable en ningún lugar, ni siquiera para uno mismo. (p. 207).

En consecuencia, y ante las múltiples identidades que permite crear la web, los individuos terminan por adoptar caretas en desmedro de su esencia original.

Por otra parte, esta inmersión de las innovaciones digitales, enmarcadas en una sociedad de corte consumista, en la vida cotidiana de las personas ha desencadenado un contexto que el filósofo Zygmunt Bauman ha denominado como proximidad virtual, el cual ha hecho de "las conexiones humanas algo a la vez más habitual y superficial, más intenso y más breve. Las conexiones suelen ser demasiado superficiales y breves como para llegar a ser un vínculo" (Bauman, 2006, p. 87). Las personas se sienten más próximas al estar interconectadas por la red, pero ello no es sinónimo de una cercanía de carácter amical. Asimismo este concepto está englobado en un cambio mucho más profundo a nivel sociocultural: el del ámbito de la sexualidad. Es así que Bauman (2006) teoriza acerca de una sexualidad líquida como aquel momento histórico en el que ya no se habla de relaciones sino de conexiones entre seres humanos en tanto estas últimas no cargan con los pasivos de las primeras. Son menos duraderas dado que pueden ser cortadas abruptamente cuando el individuo así lo desee, menos riesgosas pues al no existir un férreo compromiso entre las partes más que el goce y el placer nadie resulta herido o vive con la inseguridad latente de ser abandonado, y posibilita la capacidad de buscar nuevas y más satisfactorias conexiones cada vez que una conexión agota su atractivo inicial. De esta manera, el sexo sin sentimientos de por medio se ha tornado una "forma de garantía confiable de reembolso económico, y los compañeros de un 'encuentro puramente sexual' pueden sentirse seguros, sabiendo que la ausencia de 'ataduras', compensa la molesta fragilidad de su compromiso" (Bauman, 2006, p. 73). 
Otro aspecto que caracteriza a este nuevo tipo de usuarios que pobla ansiosamente las redes es su marcado egocentrismo, derivado de las ansías de figuración que manifiestan al exponer su intimidad ante una audiencia global. Ellos quieren ser observados y creen que merecen estar en el foco de atención. Empero, el filósofo francés Gilles Lipovetsky (2000) va más allá y resalta que este hedonismo contemporáneo está acompañado de una banalidad en el contenido expresado:

Cuantos mayores son los medios de expresión, menos cosas se tienen por decir, cuanto más se solicita la subjetividad, más anónimo y vacío es el efecto... nadie en el fondo está interesado por esa profusión de expresión con una excepción: el emisor o el propio creador. (p. 14).

Cabe resaltar que, para Baudrillard (2008), este afán de exposición de la vida íntima es consecuencia de factores externos y no de una voluntad propia del individuo. En otras palabras, existe una demanda de exteriorización de lo privado impuesta por las dinámicas de la comunicación contemporánea y por una cultura espectacularizada. Sin embargo, Sibilia (2008) difiere de ese argumento y sostiene que los individuos claudican libremente de su privacidad para hacerse más visibles en la red. Los usuarios no desean el anonimato pues, de lo contario, estarían condenados a la invisibilidad en la web.

Para Lipovetsky (2000) este deseo de visibilidad se enmarcaría en la búsqueda del individuo por evadir el miedo congénito a quedarse solo. Exponer sus más íntimos secretos, motivaciones y emociones les granjearía la atención de una audiencia virtual y la evasión de un estado de anonimato que los sentenciaría a la soledad absoluta. Ello debido a que la lógica de la web es que si no te ven, no existes.

En síntesis, el afán de visibilidad de este nuevo tipo de usuarios, apoyados en el avance tecnológico, así como el estado espectacularización en el que se encuentra sumida la sociedad contemporánea han terminado por reconfigurar la tradicional noción de intimidad. 
El otrora territorio de lo privado y lo secreto se ha convertido en un espacio de exposición público de la vida cotidiana.

\section{Características de los foros sobre prostitución y sus usuarios}

En lo que respecta a la literatura reciente respecto al objeto de estudio de este trabajo -foros de internet sobre prostitución-, cabe resaltar que la línea investigativa no es abundante pero sí significativa. En ese sentido, son pioneras las investigaciones de Thomas J. Holt y Kristie R.Blevins (2007), quienes analizan diversos aspectos de la subcultura representada por los usuarios de estos foros. Estos autores señalan que el anonimato es uno de los principales atractivos que brindan estos espacios virtuales, puesto que permiten a los foristas intercambiar pareceres sobre sus experiencias sexuales sin ningún tipo de estigmatización social. En esa misma línea, Cáceres, Ruiz y Brändle (2009) afirman que, en estos nuevos espacios de socialización online, el anonimato les permite a los usuarios interpretar diversos personajes al momento de relacionarse con otros. Además, la capacidad que demuestren para cumplir a cabalidad con estos roles inventados está directamente relacionada con el nivel de aceptación y rechazo que logren con su nueva imagen.

Algunas investigaciones también han determinado que la principal función de los foristas es compartir información -lo más detallada posible- acerca de sus encuentros sexuales con prostitutas. Por ejemplo, para Rocha, Liljeros y Holme (2010), la finalidad última de esta práctica comunicativa sería la evasión de posibles fiascos: decepciones o -en el peor de los casos- estafas en torno al tipo y la calidad de servicio que una meretriz dice brindar.

No obstante, no todos los usuarios participan de manera activa, existen algunos que se limitan a observar el flujo de información, ya sea por mero ocio o por beneficiarse de éste. Empero, para Casaló, Flavián y Guinalíu (2011), los usuarios pasivos son igualmente importantes para el foro dado su potencial como futuros usuarios activos. En consecuencia, estos autores resaltan la importancia de la noción de reciprocidad porque robustece el 
sentido de responsabilidad de los usuarios. Es decir, éstos se sienten exhortados a retribuir activamente a la comunidad virtual con el mismo tipo de beneficios que han obtenido de ella cuando participaban de manera pasiva.

En efecto, la aglomeración de los usuarios, activos e inactivos, que se articulan en torno a estos foros conforman lo que se ha denominado como comunidad virtual. Para Chao-Min, Meng-Hsiang y Wang (2006), éstas son consideradas espacios donde un cúmulo de individuos con intereses similares interactúa mediante el intercambio de información y experiencia. Por otra parte, los objetivos comunes que comparten los miembros de la comunidad les facilita la interpretación del conocimiento que intercambian y eso se traduce en un incremento tanto de la calidad como de la cantidad del mismo.

Regresando al carácter de los foristas, Ashford (2008) encuentra que el perfil de las personas que consumen prostitución sigue vigente en la era de internet. En otras palabras, los usuarios de estos foros comparten similares características con sus pares que frecuentan prostitutas del modo tradicional. En primer lugar, estas personas buscan concretar un acto sexual en específico e internet les permite encontrar a las mujeres idóneas para concretar sus fantasías. En segundo lugar, están motivadas por la posibilidad de tener diversos encuentros sexuales con diferentes mujeres. En tercer lugar, y ligado a lo anterior, pueden tener relaciones con mujeres con rasgos particulares en tanto la red les permite hallar mujeres con un fenotipo o personalidad específica. En cuarto lugar, les satisface el hecho de estar cometiendo un acto socialmente transgresor. Y, finalmente, se sienten atraídos por la naturaleza limitada y no emocional que implica el contacto con las trabajadoras sexuales.

Con respecto a la naturaleza de las publicaciones vertidas en estos foros, Holt y Blevins (2007) han identificado una particularidad en el discurso de los foristas: el uso de un sociolecto caracterizado por el empleo de jergas acordes al tema. Es decir, los usuarios emplean un argot para referirse a diversos aspectos de sus aventuras sexuales como el tipo y la apariencia física de su acompañante, la calidad del encuentro sexual y las posibles 
restricciones impuestas por las autoridades legales. Por su parte, Libertad Borda (2006) agrega que en estos intercambios signados por una escritura informal es capital que los usuarios generen un mínimo consenso sobre el significado de las jergas empleadas para que todos puedan comprenderse.

La particularidad de este tipo de sociolecto apunta hacia una cosificación del cuerpo femenino. Esta circunstancia parece ser característica de los relatos de índole sexual, pues, de acuerdo con Nasiri, Rostami, Bagher y Bakhshandeh (2014), estos se refieren a las personas como meros objetos libidinosos, sin ningún tipo de emoción más que la pulsión sexual. En esa misma línea, Holt y Belvins (2009) sostienen que la terminología empleada por los foristas para referirse a las meretrices tiene como fin resaltar su condición de producto carnal.

Asimismo, tanto las investigaciones de Rocha, Liljeros y Holme (2010) como la de Holt y Belvins (2007) coinciden en que los usuarios califican sus encuentros sexuales en base a una serie de factores: el aspecto físico, el tipo de servicio sexual, el precio, el trato, la calidad del perfomance sexual y los riesgos, etc. Además, resaltan que los foristas intercambian datos útiles para contactar a determinadas prostitutas. A su vez, para estos autores, es el tipo de trato brindado por las meretrices lo que más valoran los usuarios del foro. En ese sentido, las prostitutas que se muestran frías durante el coito suelen tener calificaciones negativas. En contraste, aquellas que se entregan por completo durante el performance y aparentan disfrutarlo reciben críticas positivas. Éstas últimas suelen ser quienes brindan un trato de pareja (girlfriend experience), entendido como aquella situación en la cual la prostituta aparenta gozar las relaciones sexuales con su cliente como si no hubiese un pago de por medio.

Ahora bien, esta sobreexposición de la vida sexual en el mundo virtual refleja la difuminación de la línea que separaba la vida privada de la pública. Al respecto, Sabater (2014) cree que el avance tecnológico de los nuevos medios ha facilitado este proceso pues 
las tecnologías de la información (TIC) tienen la potestad de impregnar completamente la cotidianidad de las personas. De esta manera, lo privado deviene en público en tanto las TIC desdibujan y ensanchan los bordes del tiempo y el espacio.

Finalmente, Pérez (2012) arriba a la conclusión de que las prácticas observadas en los foros son evidencia del surgimiento de nuevas formas de socialización, empleadas para relacionarse con otros usuarios tanto a través de la web como fuera de ella. En otras palabras, en la actualidad se están reconfigurando las formas tradicionales de socialización e identificación entre individuos.

\section{Metodología}

Esta investigación optó por combinar dos tipos de metodología para obtener los resultados deseados. Por un lado, se emplearon matrices cuantitativas para realizar un análisis lingüístico del sociolecto de los foristas y una evaluación de la plataforma. Y, por otro, se utilizaron variables semióticas de carácter cualitativo para identificar las dinámicas tensivas subyacentes en el discurso de los foristas. Para ello, se tomaron como muestra 100 posts de diversas subsecciones del foro peruano Zona Caleta (ver anexo 1) publicados a lo largo del 2015. Por ejemplo, se tomó 5 posts de la subsección “Independientes - Cono Norte”, 5 de “ Night Clubs - Zona Exclusiva” y así sucesivamente. Éstos fueron examinados a través de las tres matrices cuyo propósito final era analizar las formas discursivas que caracterizan a este tipo de usuarios.

En la primera se intentó hallar particularidades lingüísticas tales como el uso de palabras clave, figuras literarias y formas de enunciación. En la segunda se propuso un análisis tensivo a partir de tres conceptos semióticos. El estado de la experiencia buscó identificar qué sensación del eje tímico habían transitado los usuarios tras el coito: euforia (placer) o disforia (displacer), y qué elementos la determinaban. Estas categorías permiten evaluar la representación virtual de las sensaciones que los usuarios del foro señalan haber 
experimentado en tanto organismos que perciben subjetivamente la realidad a través de la atracción y la repulsión. (Greimas, 1989). Por otra parte, los esquemas tensivos, plano en el que se conjugan las dimensiones de intensidad y extensidad, posibilitan conocer la disminución o aumento del grado de tensión en la imagen virtual del sentimiento (placer/displacer) que los foristas manifiestan haber sentido. (Fontanille, 2006). Y, por último, los modos de presencia permiten, mediante la mira que mide la intensidad y la captación la extensión, conocer en qué medida los usuarios consiguen (o no) satisfacer necesidades particulares y si estás afectan la representación virtual de su sensación final de placer/displacer. (Fontanille \& Zilberberg, 2004).

En la tercera matriz se analizó el foro en tanto plataforma digital. Se recolectó data acerca de la presencia de elementos característicos de éste como: avatars, emoticones, elementos multimedia, links, mensajes finales y réplicas. Además, se hizo una aproximación hacia el tipo de affordance (instrucciones para interactuar con la plataforma) que existe en el foro y si es que esta se cumple o, por el contrario, se incumple generando breakdowns (cortocircuito producido por el incumplimiento de las normas de interacción). En adición, también se aplicó el modelo sociosemiótico elaborado por Carlos Scolari para entender el contrato de interacción establecido entre el creador de la interfaz (foro) y los usuarios, debido a que los soportes digitales no son neutrales o transparentes, también comunican por sí mismos. (Scolari, 2004).

\section{Tipos y significados de las palabras clave}

Se ha denominado como palabras clave a todos aquellos vocablos de carácter coloquial que usan los foristas al momento de describir sus experiencias sexuales. En ese sentido, el análisis arrojó que éstos emplean en promedio 38 palabras clave por post. Estas jergas son utilizadas para describir diferentes momentos de la experiencia sexual de manera figurativa y lúdica. 
Los foristas las emplean para referirse a las trabajadoras sexuales ("merecas", "kines", "nenas", "rufianas", “polillas") y a ellos mismos (“cofrades", “caletas", “colegas"). Además, con respecto a la edad de las meretrices, los usuarios diferencian claramente entre las de menor edad ("chibola", "colegiala") y las de mayor edad ("milf", "tía", "veterana"). También es común el uso de este argot para hablar sobre la anatomía femenina y masculina, particularmente de los órganos sexuales de ambos. Así, en el caso de las mujeres, se hace alusión a sus senos ("tetas", "mangos", "melones", "terezas"), vagina ("papita", "concha", "papaya", "molleja"), ano ("anis", “anibal", "anillo", "ortega", "ojete") y trasero ("culo", "rabo", "cola", "panetón"). Y en el caso de los hombres a su pene ("pinga", "muchacho", "pájaro", "ñaño", "soldado", "mazo") y, en menor medida, a sus testículos ("bolas", "huevos", "boloñas", "gemelos").

Los usuarios del foro se explayan aún más en sus definiciones cuando les toca describir el acto sexual ("polvo", "mate", "cache", "inmolada"). Por ejemplo, emplean términos para relatar el desempeño de las prostitutas durante el coito ("cabalgar", "ajustar", "montar"), pero también el suyo propio, el cual está directamente ligado al acto de penetración (“clavar", "zampar", "taladrar", "bombear", “embestir”). Del mismo modo, las posturas sexuales practicadas también reciben variopintas calificaciones ("doggie", "misionero", "cowboy", "ranitas", "cucharita"), particularmente cuando se hace referencia al sexo oral ("mamey", "gp", "fellatio", "karaoke", "chupada"). Cabe resaltar que también se emplean ciertos términos para aludir a algunos objetos como los preservativos ("jebe", "poncho", “condorito", "pre”) y el dinero ("bloodys", "lucas", "maracas", "lucrecias").

Ahora bien, al observar el uso de esta terminología se entiende que existe un consenso tácito entre los usuarios del foro sobre el significado de la vasta cantidad de jergas, pues de lo contrario no se entenderían. Además, pese a que no se explicita en ningún lugar del foro qué significa cada palabra, los foristas se ven ayudados por el contexto en el que éstas se inscriben. Por ejemplo, si se lee "130 bloodys" en el apartado dedicado a la descripción del precio, se sobreentiende que se está haciendo referencia a la cantidad de dinero que cuesta el servicio, en este caso 130 soles. 
Otro aspecto que resalta de este tipo de sociolecto es la alusión que se hace del cuerpo femenino como si fuera un mero objeto sexual. No solo por la naturaleza de los términos empleados para referirse a sus partes íntimas, sino porque al momento de describir el coito las mujeres aparecen como un elemento cuya única función es brindar placer al hombre, desprovistas - y acaso prohibidas- de toda capacidad emotiva. Por su parte, los clientes, con el fin de demostrar su virilidad, abordan su experiencia como un sometimiento de su concubina de turno. En ese sentido, es esclarecedor el siguiente extracto del relato del usuario dany29_05 (2015):

Ahí es donde se la da por hablar y hablar de no se cuanta wepada q me daba ganas de decirl [sic] perra solo vengo a cachar si quisiera hablar me buzco una pinky enamorada chibola para hablar de esa mierda con ella y no contio.

\section{Recurrencia y uso de figuras literarias}

Durante el análisis de los posts también se logró identificar que los usuarios emplean diversas figuras literarias al momento de narrar sus experiencias sexuales. Las metáforas son las que encabezan la lista de preferencias con una presencia del $68 \%$ sobre el total de las publicaciones. Éstas son empleadas en su gran mayoría para describir erecciones (“en one se armó la carpa", “despertar al muchacho", "levantar al muñeco") y eyaculaciones ("vomite toda la vitamina", "se me vino el huayco", "escupí todo el quaker"). También se aplican, aunque en menor medida, al hacer referencia a determinadas prácticas como el sexo oral (“mandó saludos a la cofradía", "pasó a saludar un buen rato").

En el segundo lugar de las preferencias se encuentran los símiles con un 64\%. Los usuarios los emplean para categorizar a las trabajadoras sexuales ("mamacita de video de reggaeton misio", "chibola de primeros ciclos de universidad de cono", "señora de pollada") y para comparar partes de su cuerpo ("sus labios vaginales eran como dos crestas 
de gallo", “(senos) como los de shirley arica cuando salió en el guachimán”, "tiene los cachetes de kiko"). También para relatar el coito ("lo chupaba como si comiera un marciano", "se empezó a mover como el cuy rápido rápido", “aproveche a prenderme de ellas como bebe hambriento") y calificar el trato de la prostituta ("te trata como si fueras su marido", "el sexo fue como si tirara con mi mujer", "como de amante salvaje"). Estas comparaciones, caracterizadas por un lujurioso sentido del humor, tendrían como objetivo narrar los hechos de la manera más gráfica posible para que otros usuarios puedan entender y beneficiarse con esa información.

En el tercer lugar se encuentran las hipérboles con un 53\%. Aquí se puede apreciar una clara intención de los usuarios por exagerar su propio desempeño y potencia sexual ("se tenía que sostener de la cama sino la estampaba contra la pared", "espero que no se le haya volteado el estómago", "sentía como chocaba contra la entrada de su útero"). Otro uso recurrente de hipérboles se presencia en las descripciones de la vagina de las meretrices. De acuerdo con los foristas éstas pueden estar muy 'usadas' (“está como la Javier Prado pasa de todo", "papasa entra el Metropolitano") o no, y en ese caso brindar un mejor rendimiento ("su papa realmente estrangulaba mi verga", "su papaza oprimió a mi pajarraco"). Por último, estas figuras literarias también son empleadas para enaltecer la sensación de placer ("me enferma tenerla en veinte uñas", "en esa pose mi cerebro iba a reventar").

En cuarto lugar están las onomatopeyas con una presencia del 48\%. Su uso le agrega un mayor sentido de oralidad a los textos al imitar sonidos de la realidad como risas (“jajaja", "jejeje”), gemidos de placer (“ahhh", "ufff”) y ruidos que evocan al coito ("plac plac plac", "plashhhh", "plas plas”). Finalmente, se encuentra la presencia de sinonimias en menor medida con un $15 \%$. Éstas se usan tanto para darle un mayor ritmo a la narración como para enfatizar una acción en particular ("mis manos las agarran, las sujetan, las ordeñan”, "los lamí, mordí y succione a mi gusto”, "se comió, chupó, succionó mi arma totalmente"). 
No obstante, uno de los datos más significativos se halla al cruzar las diferentes variables de este apartado. Así, se evidencia que en el $96 \%$ los posts se emplea al menos una figura literaria de las cinco en cuestión. Esta circunstancia abogaría por una ficcionalización de la experiencia sexual en tanto estas figuras son propias y oriundas de las ficciones literarias. Al emplearlas -tal vez inconscientemente- los foristas imprimen a sus narraciones de tintes novelescos que los hacen más llamativos y creativos. Asimismo, los foristas siguen un esquema narrativo clásico compuesto por un inicio (el abordaje a la meretriz), un desarrollo (la consumación del acto sexual) y un final (la sensación de placer o displacer luego del coito).

\section{Frecuencia y empleo de formas de enunciación}

A lo largo del análisis de la muestra elegida también se ha constatado el uso de diversas formas de enunciación para citar los diálogos entre los individuos implicados en la narración. La enunciación indirecta, caracterizada por el parafraseo de las conversaciones, fue la más recurrente con un $38 \%$. Por su parte, la enunciación directa, donde se citan las frases exactas (con comillas o guiones literarios) de los implicados, contó con un 10\%. Además, se registraron un $28 \%$ de casos en los que se usaban ambos métodos y un $24 \%$ en los que no se empleaba ninguno.

Si se realiza el cruce de variables de este apartado se revela que en el $76 \%$ de los casos existe al menos una forma de enunciación. Este patrón obedecería al hecho de que estas formas enunciativas le brindan un mayor sentido de oralidad al texto. A su vez, esto le otorgaría mayor veracidad al testimonio de los foristas pues se trata de citas (directas o indirectas) de sujetos involucrados directamente en la narración.

Por otra parte, y siguiendo la misma línea del apartado anterior, esta recurrencia indicaría también una ficcionalización de la experiencia sexual, pues se está dotando a los 
sujetos involucrados en la experiencia de líneas de diálogo propias de las obras literarias. De esta manera se convierte paulatinamente a los individuos en personajes, a los cuales vamos conociendo más, psicológica y físicamente, a medida que avanza la narración del encuentro sexual, el cual se reconfigura a su vez como un relato basado en hechos reales. Al respecto, es significativa la reproducción del siguiente diálogo consignado en la narración del usuario orgasmico (2015):

— ¿Dónde esta el timbre de este antro? - me dije, y al costadito me doy cuenta que había una ventanilla misma boletería y escucho una voz femenina algo faltosa que me dice:

—Un sol la entrada flaco

- ¿Se encuentra la pechugona Jessi? - le pregunte todo cacherazo

-No se, pero si vas a entrar paga tu luca — me contesto toda faltosaza

\section{Estado de la experiencia del usuario: placer o displacer}

En el 74\% de los casos los usuarios señalan haber tenido una experiencia eufórica (placer), mientras que el 26\% manifiesta que su experiencia fue disfórica (displacer). Las categorías que determinaron estos estados son: aspecto físico (55\%), trato (67\%), performance (69\%) y precio $(2 \%)$. Ergo, los datos indicarían que, al momento de calificar sus encuentros sexuales, los usuarios priorizan, en primer lugar, el perfomance de la meretriz durante el coito y, en segundo lugar, el tipo de trato que reciben de parte de estas.

No obstante, si se toma en cuenta solo las experiencias eufóricas los porcentajes varían un poco. Si bien el performance se mantiene a la cabeza (70\%), ahora el aspecto físico cobra igual importancia que el trato (ambos con 66\%). Por el contrario, si se considera solo las experiencias disfóricas los porcentajes varían aún más. En este caso es el trato el que lidera las categorías (73\%), seguido del perfomance (62\%) y el aspecto físico $(23 \%)$. 
Estas variaciones indicarían que las preferencias de los foristas cambian de acuerdo al estado de la experiencia en el que se encuentran después del coito. Si han experimentado placer, la variable aspecto físico eleva su importancia en su calificación final. Por el contrario, si han experimentado displacer, la variable trato es la que se erige como la más relevante en su evaluación. Ambas situaciones revelan intenciones y preferencias ocultas que los usuarios no manifiestan directamente, a menos que se realice este cruce de variables.

\section{Implicancias de los esquemas tensivos en la experiencia del usuario}

Luego de analizar los textos de los foristas se halló la presencia de los siguientes esquemas tensivos: amplificación (78\%), atenuación (5\%), decadencia (3\%) y ascendencia (28\%). Se llegó a estos resultados empleando las siguientes variables cuantificables para medir la extensión del placer/displacer (valor) de los clientes (centro de referencia): la edad de las meretrices, el precio que cobraban por sesión y el tiempo que duraba esta.

Como se puede apreciar, el esquema de amplificación se impone a los demás. A su vez, la variable que determina la presencia de este esquema con más frecuencia es el tiempo. Por consiguiente, cuando la experiencia es eufórica, al ser más prolongada la sesión, mayor es el placer experimentado por el cliente pues disfruta más del coito con una meretriz que es de su agrado (Figura 1). El usuario bloody_angel (2015) pone de manifiesto esta premisa al relatar en su evaluación lo siguiente: "El segundo polvo fue más intenso y de mayor duración, sentí que se humedeció algo su parte, hicimos las poses que nos faltaban". Incluso existen usuarios como Siglanvir (2015) que aseguran contener su eyaculación para que la sesión sea más duradera y, por ende, más placentera: "Después se montó encima mio, ella es muy complaciente y empezó a moverse a lo loco, queriéndome que bote mi leche, pero me contuve". 


\section{Figura 1}

Esquema tensivo eufórico según la variable tiempo

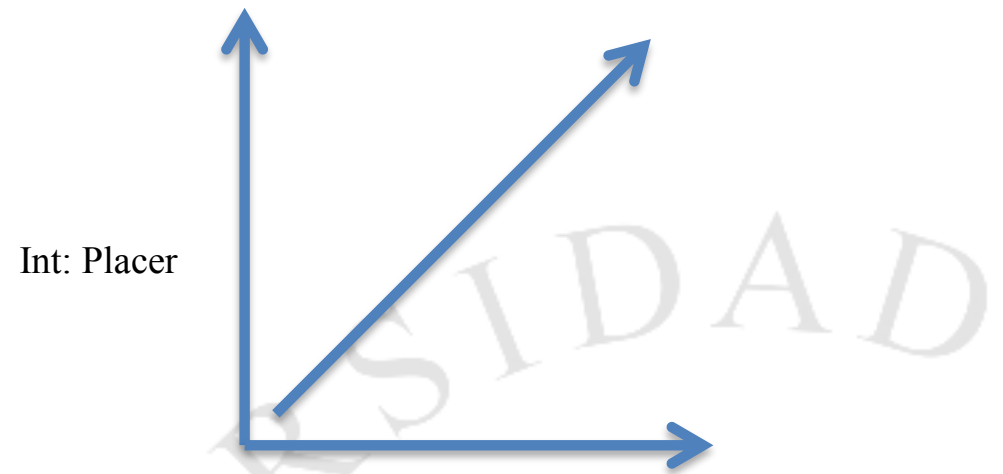

Ext: Tiempo

Por el contrario, cuando la experiencia es disfórica, al ser más prolongada la sesión, mayor es el displacer del cliente pues está obligado a permanecer más tiempo con alguien que le disgusta o que no lo trata bien (Figura 2). Esta situación llega hasta el paroxismo cuando los usuarios, como El_Muki (2015), señalan que prefieren no concretar un orgasmo a permanecer más tiempo al lado de la meretriz: "La flaca se movía muy poco y se notaba media fría, tanto desde el principio como en el cache, no me vine, me cambié y fui en busca de otra pa botar el quaker".

\section{Figura 2}

Esquema tensivo disfórico según la variable tiempo

Int: Displacer

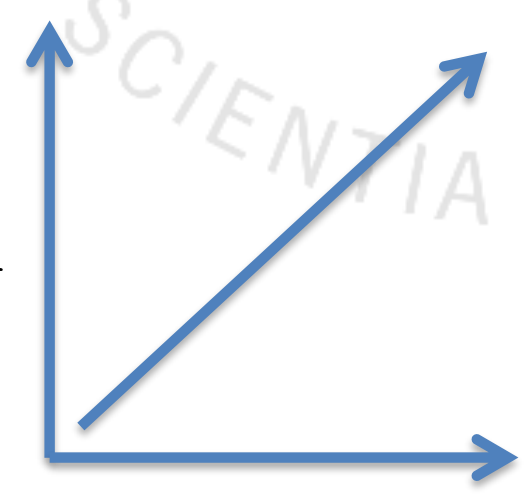

Ext: Tiempo 
Otra variable que también determina el esquema de amplificación, aunque en menor medida, es el precio. Por ello, cuando la experiencia es eufórica, al elevarse el precio también se incrementa la sensación de placer del cliente (Figura 3). Esto se debe a que una mayor inversión permite acceder a otras opciones placenteras como: sexo anal, sesiones extra, salidas a un hotel (en caso la prostituta trabaje en un local) u otro tipo de beneficios. Al respecto, es figurativo el relato del usuario Josmat271 (2015):

Primero se quitó la ropa excepto el sostén, cuando le pedí que se lo quitara también me dijo así nomás, entonces le ofrecí un adicional para que se saque el sostén, lo pensó, hizo su contraoferta y al final quedamos en que por el adicional se quitaba el sostén y daba besos. Entonces cambió completamente su trato, con lo cual realmente me calenté, me besó el pecho con mucha sensualidad y luego me dio un beso con lenguita y empezamos a manosearnos y revolcarnos en la cama como locos con besos y chapes al antojo del cliente.

\section{Figura 3}

\section{Esquema tensivo eufórico según la variable precio}

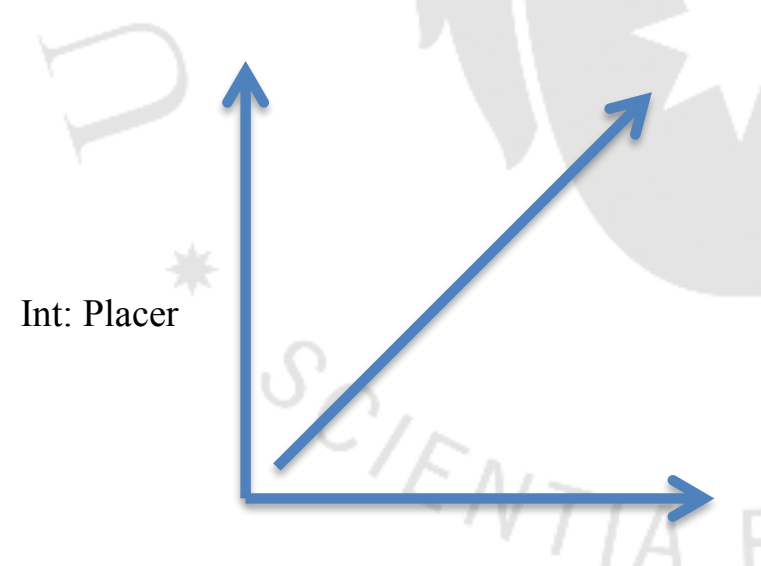

Ext: Precio

Por último, el otro esquema que presenta cierta recurrencia, aunque menor que el de amplificación, es el de ascendencia. Y es aquí que la variable edad cobra importancia como determinante de este esquema. Por ello, cuando la experiencia es eufórica, a menor edad de la prostituta, existe una mayor sensación de placer del cliente (Figura 4). Esto evidenciaría 
la predilección de un grupo de usuarios por las meretrices jóvenes en desmedro de las mayores. Pese a que estas últimas gozan de mayor experiencia, los resultados indicarían que los clientes se decantan por las mujeres recién iniciadas en el mundo de la prostitución. En esa línea, el relato del usuario loki (2015) ejemplifica este tipo de preferencia: "En ello, por el tercer pabellón a la derecha veo a Kassandra con una peculiar sonrisa que incita inocencia y excitación por coger a una chibola inocente jojojojo". Además, existen usuarios como oleroso (2015) que incluyen la edad de la prostituta como un elemento importante de su evaluación: "6.5 si estuviera mas joven lleagria [sic] a puntaje mayor".

Figura 4

Esquema tensivo eufórico según la variable edad

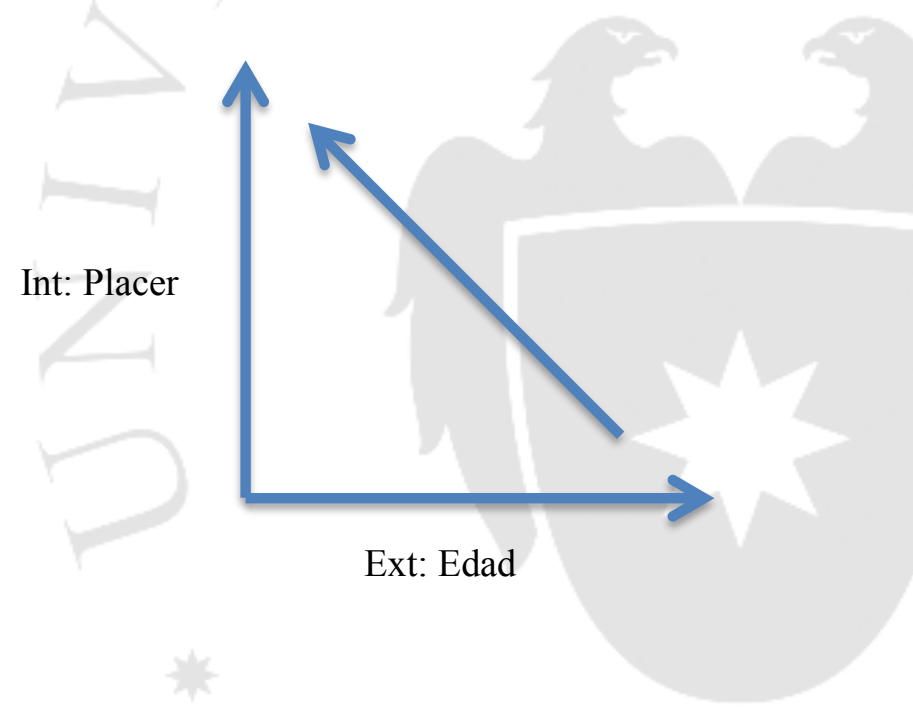

\section{Modo de presencia experimentados por los usuarios}

Los resultados para los modos de presencia fueron los siguientes: plenitud (88\%), carencia (28\%), inanidad (16\%) y vacuidad (2\%). En ese sentido, el patrón que definió el estado de plenitud fue el cumplimiento del coito. Es decir, los clientes manifestaron una mira intensa por la meretriz y su capacidad fue extensa puesto que concretaron un orgasmo con ella. Esto aplica tanto para las experiencias de placer como de displacer. Sin embargo, cuando se trata de experiencias de displacer, a pesar de que los clientes han cumplido su objetivo (orgasmo), su sensación final es la de no haber disfrutado del todo la sesión: es un placer vacío. 
Con respecto al estado de carencia, la variable que se manifestó con mayor frecuencia fue la de no acceso al sexo anal. Los clientes poseían una mira intensa por este particular tipo de servicio, pero se topaban con una capacidad restringida dado que las trabajadoras sexuales no lo ofrecían. No obstante, este impase no opacó la sensación final de placer que experimentaron.

Por otra parte, a pesar que es minoritario, también es interesante abordar el estado de inanidad. Aquí, los clientes cuentan con una mira débil pues les desagrada algún aspecto de la prostituta, pero cuentan con una capacidad extensa dado que concretan el orgasmo. Ellos hacen esto ya sea porque ya pagaron o porque desean satisfacer su libido a toda costa, a pesar de que la sensación final no sea placentera.

\section{Affordances / Breakdowns: (in)cumplimiento de las normas de la plataforma}

Antes de empezar con el reconocimiento del affordance propio del foro ZonaCaleta, cabe recordar que este representa las instrucciones de uso para interactuar con la plataforma. Hay que agregar también que existen dos tipos de affordances: los funcionales, que solo informan sobre las instrucciones, y los sociales, que hacen competentes a los usuarios al permitirles regular el código de interacción de la plataforma. (Scolari, 2004).

En ese sentido, el foro ZonaCaleta se caracteriza por tener un affordance funcional. Ello debido a que, en un apartado denominado "Normas del foro Zonacaleta.com" (ver anexo 2), se explicita una serie de reglas de comportamiento para el correcto uso del sitio. Ahí, los administradores señalan que está prohibida la pedofilia, el acceso a pederastas, la publicación de contenido homosexual, etc. Además, se hace énfasis en la jerarquía dentro de la comunidad, donde los administradores y moderadores deben ser tratados con respeto. Por último, se presenta la plantilla (ver anexo 3) que todos los usuarios deben usar para calificar sus encuentros sexuales y un tutorial acerca de cómo subir contenido multimedia. 
En otras palabras, se establece una comunicación vertical pues las reglas han sido creadas de manera arbitraria por un pequeño grupo de usuarios y al resto no le queda más que acatarlas o afrontar las consecuencias.

Cuando estas normas se incumplen es cuando se producen breakdowns, vale decir, un mal funcionamiento en el código de interacción de la plataforma. (Scolari, 2004). Cuando esto sucede, el equipo de moderadores coloca un aviso de advertencia al final (ver anexo 4) del post infractor, recalcando el tipo de falta en el cual ha incurrido el usuario. Y si las faltas son recurrentes se procede a la inhabilitación temporal o definitiva de la cuenta según la gravedad del caso.

No obstante, existen breakdowns que colaboran con la evolución de la plataforma. Por ejemplo, en el foro en cuestión existen dos normas que prohíben el uso de mayúsculas y de abreviaturas en los posts. Además, se insta a los foristas a escribir correctamente para una mejor comprensión y lectura del foro. Si estas reglas se hubieran cumplido a rajatabla posiblemente nunca se hubiera gestado el sociolecto que en apartados anteriores se ha descrito. Quizá por ello es que el equipo de moderación no ha sancionado estas conductas, pues han contribuido con el desarrollo del foro al brindarle un elemento que es parte de su sello distintivo.

\section{Modelo sociosemiótico: la plataforma como generador de significado}

El modelo sociosemiótico propuesto por Scolari (Figura 5) parte de la premisa de que la interfaz -el foro ZonaCaleta en este caso- es un espacio donde confluyen e interactúan dos gramáticas: la del diseñador implícito y del usuario implícito. El primero hace referencia a la imagen del creador de la interfaz que tiene el usuario en su mente y el segundo a la imagen del usuario ideal que el creador ha concebido para que use su interfaz. Ambas categorías entablan una propuesta de interacción, entendida como un diálogo virtual. Asimismo, las dos son extensiones virtuales de sus verdaderas identidades en el mundo 
offline, es decir, del diseñador empírico (el creador real de la plataforma) y del usuario empírico (la persona real tras la pantalla). Este último puede o no aceptar un contrato de interacción, que implica ingresar en un mundo que funciona bajo su propia lógica y que tiene normas que deben ser acatadas para interactuar con la interfaz. Por otra parte, el diseñador empírico concibe un modelo del diseñador, esquema mental de cómo va a funcionar su interfaz, y el usuario empírico un modelo del usuario, esquema mental de cómo funciona la interfaz a partir de su interacción con esta y de su propio bagaje intelectual. (Scolari, 2004).

Figura 5

Modelo sociosemiótico de la plataforma

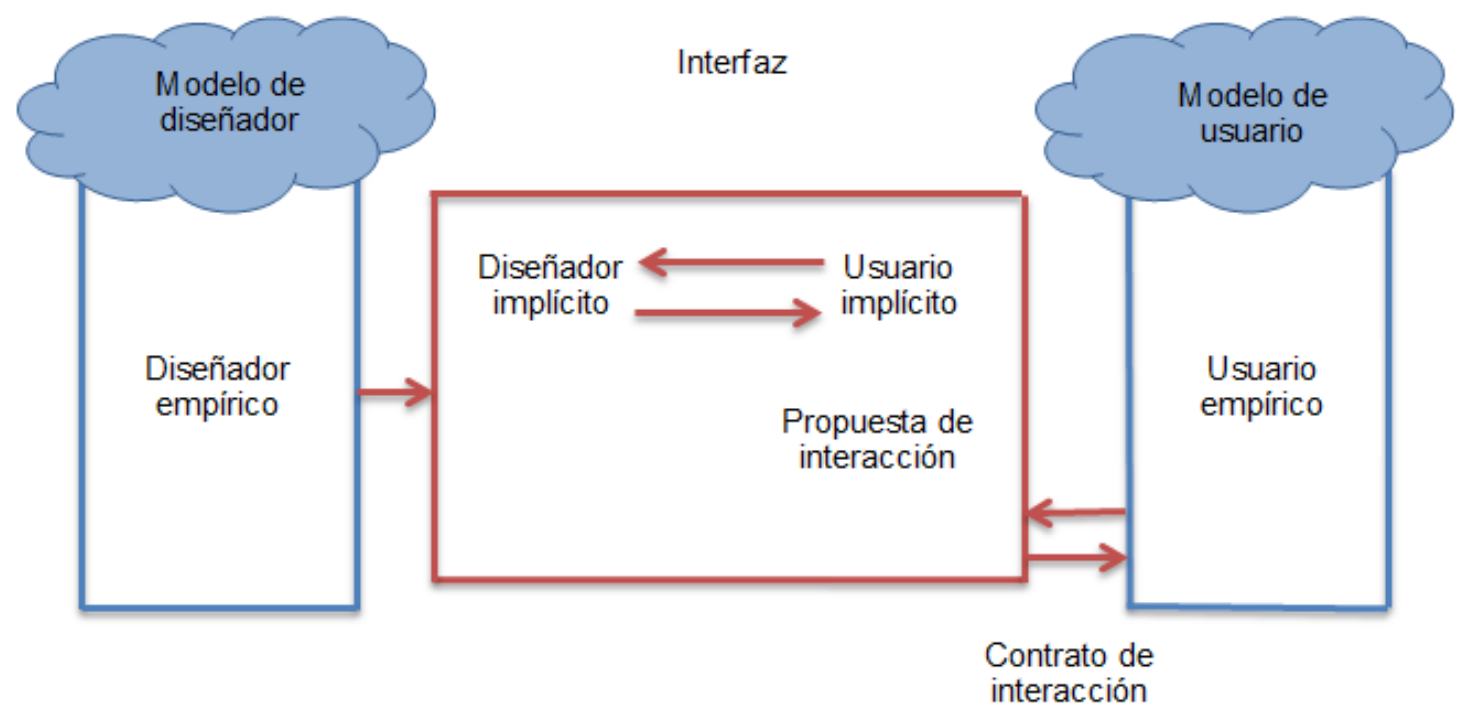

Ahora bien, en el caso del foro ZonaCaleta, el diseñador implícito que imaginan los foristas es el administrador conocido como SP3KTRVM. Por su parte, el administrador concibe dos potenciales usuarios implícitos: los activos y los pasivos. Con los primeros, en tanto entiende que frecuentan a trabajadoras sexuales, establece una propuesta de interacción en la cual demanda que compartan su experiencia y conocimiento sobre sus 
encuentros sexuales con meretrices con el resto de usuarios. Además, estos deben aceptar el contrato de interacción que consiste en ceñirse a las normas de comportamiento del foro si es que quieren publicar o hacer comentarios. En cambio, con los segundos, puesto que pueden ser cualquier tipo de usuario, la propuesta de interacción es casi nula pues el administrador solo se limita a dejar que estos observen el contenido del foro ya sea por curiosidad o por ocio.

Cabe resaltar que no es materia de esta investigación determinar si la figura del diseñador implícito dista (o no) de su figura empírica y de igual manera para los usuarios. Sin embargo, lo más probable es que la figura del usuario implícito si se acerque a su correlato empírico, al menos en lo que respecta a los usuarios activos. Ello debido a que una de las claves para que la interfaz funcione correctamente, como ocurre con el foro ZonaCaleta, es que la representación implícita y empírica del usuario se acerquen lo más posible. En otras palabras, que el usuario ideal imaginado por el diseñador se corresponda con su figura real tras la pantalla del ordenador.

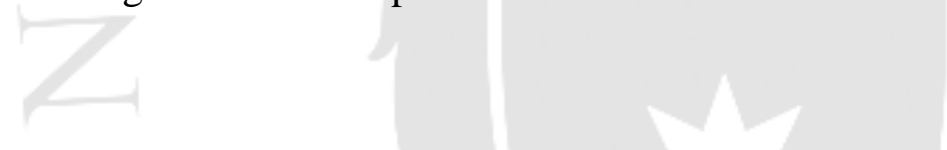

En cuanto a los modelos mentales de cada uno, el del diseñador se hace tangible en la formulación de las normas de comportamiento del foro. Es a través de éstas que el creador plasma la idea que tiene acerca de cómo debe funcionar su interfaz. En contraste, el del usuario está determinado por las competencias tecnológicas con las que cuenta para interactuar con la interfaz, así como sus experiencias previas con plataformas similares.

Otro aspecto que es importante resaltar es la relación entre el modelo del diseñador y el uso final que le dan los usuarios a la interfaz. En ese sentido, Scolari (2008), tomando ideas de Eco, señala que existen circunstancias en las que ocurre una subinterpretación interactiva: una interpretación incompleta de la plataforma y, por ende, un uso limitado de la misma. Esto encuentra asidero si constatamos las cifras de la tercera matriz de análisis respecto al uso de elementos característicos del foro: avatar de usuario (38\%), emoticones $(38 \%)$, elementos multimedia (18\%), links (15\%), mensaje final $(34 \%)$. A pesar de que la 
plataforma pone a disposición de los usuarios todos estos elementos, e incluso tutoriales de cómo insertar imágenes y videos, los resultados demuestran que los usuarios no hacen mucho uso de ellos.

\section{El rol de las réplicas en la plataforma}

Las réplicas son aquellos posts que se publican en respuesta a la calificación original que un usuario hace de su encuentro sexual. Su naturaleza puede ser directa (ver anexo 5), cuando los otros usuarios hacen comentarios en referencia a la calificación original, o indirecta, cuando los otros usuarios visitan a la misma prostituta y hacen sus propias calificaciones. En ese sentido, los resultados fueron: réplicas directas (31\%), réplicas indirectas (46\%), ninguna de las dos (23\%).

Si se realizan los cruces de variables se constata que en un $77 \%$ de los casos se presenta algún tipo de réplica, ya sea directa o indirecta. Esto indicaría el alto grado de interactividad que existe en este espacio virtual. Y a su vez que la comunidad comprende que su subsistencia depende del intercambio de información acerca del desempeño de las meretrices y del feedback entre usuarios para corroborar o confrontar los testimonios.

\section{Discusión}

El primer punto que se ha cubierto mediante esta investigación es la descripción de las particularidades lingüísticas de los usuarios del foro ZonaCaleta. En ese sentido, destacan el amplio y variado repertorio de jergas empleadas para relatar las experiencias sexuales. Al respecto, existen coincidencias con lo hallado en el estudio de Holt y Blevins (2007) pues se usan estas palabras para describir aspectos como la apariencia física y el perfomance de las meretrices. Asimismo, también se cumple lo resaltado por Borda (2006), en relación al consenso que debe existir entre los foristas para pactar los significados de estos términos informales. 
Otra arista que es importante resaltar es que, como señalan Holt y Belvins (2009) y Nasiri, Rostami, Bagher y Bakhshandeh (2014), no solo la naturaleza de este tipo de palabras sino también el de las figuras literarias tiene como sello distintivo la cosificación de la mujer. Los relatos se caracterizan por darle a las meretrices un tratamiento de mero objeto sexual cuya única finalidad es brindar placer al cliente. Por ende, sería significativo, dado que se trata de un fenómeno global, que futuras investigaciones se ocupen del estado de la cosificación de las trabajadoras sexuales.

Por otra parte, la extendida utilización de figuras literarias refuerza la idea de la existencia de una ficcionalización de la experiencia sexual. No solo porque éstas provienen del ámbito literario, sino también por el valor añadido que le brindan a los textos. Vale decir, un estilo mucho más gráfico en las descripciones y un libidinoso sentido del humor. Además, figuras como las onomatopeyas -y también la alta recurrencia de formas enunciativas- impregnan de oralidad a las narraciones. Esta circunstancia se enmarca en lo que Sibilia (2008) denominó como la ficcionalización, fenómeno que se caracteriza por tratar de hacer más real lo real. En adición a ello, en los posts de ZonaCaleta se aprecia con claridad como los usuarios se convierten a sí mismos en personajes de sus propias experiencias y vivencias, dándole así aún mayor veracidad a sus textos.

A su vez, es probable que, como en la investigación de Cáceres, Ruiz y Brändle (2009), la minuciosidad brindada por los usuarios sobre su vida sexual se deba al hecho de que el foro les permite mantener su verdadera identidad en el anonimato e inventarse una nueva personalidad virtual. Esto podría avalar la tesis de Baudrillard (2000) en referencia a que, al emplear diversas identidades en la red, los individuos terminan por perder la propia. No obstante, esa afirmación termina por ser parcialmente cierta, pues el usuario activo y asiduo de ZonaCaleta cuenta con un único perfil ya que a medida que más publicaciones haga con este, más incrementará su nivel de jerarquía dentro del foro. Cabe resaltar que esta 
mecánica de ascenso y otras prácticas socioculturales de este tipo de comunidades virtuales deberían ser estudiadas con mayor profundidad en otros trabajos empíricos.

Luego del análisis de los posts, lo que sí quedó demostrado fue el argumento de Sibilia (2008) respecto a que los usuarios renuncian voluntariamente a su privacidad para exponer su vida privada, en detrimento de la afirmación de Baudrillard (2008) acerca de que existe una imposición por exteriorizar la intimidad de parte de las actuales dinámicas comunicativas. Los usuarios de ZonaCaleta exhiben su rutina sexual libremente en aras de ganar visibilidad en el foro y así ascender en el escalafón virtual. En ese sentido, se configura lo que Landowski (1993) calificó como una práctica discursiva propia de un entorno de colectividad público dado que los foristas necesitan una audiencia para "publicitar" sus relatos, hacerse visibles y escalar en la jerarquía de su comunidad online (ver anexo 6). Además, también se percibe con claridad la premisa de Zizek (2005) respecto a que esta actividad virtual se enmarcaría como un show mediático de la vida privada. Sin embargo, no ha sido materia de este trabajo -y bien podría ser tema de otrosidentificar las causas de esta sobreexposición, las cuales podrían ser, como sugiere Lipovetsky (2000), el hedonismo de los individuos contemporáneos o el miedo que tienen a la soledad u otro tipo de factores.

El segundo punto que se desarrolló en este trabajo es el referente a las dinámicas tensivas que subyacen al discurso de los foristas de ZonaCaleta. Lo más destacable en este punto es la disyuntiva que se observa con las investigaciones de Rocha, Liljeros y Holme (2010) y la de Holt y Belvins (2007). Si bien ambos trabajos y este coinciden en los principales criterios de calificación de la experiencia sexual con meretrices, difieren en cuanto a cuáles son más importantes para los usuarios en aras de experimentar placer o displacer. Así, mientras que para estos investigadores el trato de una prostituta es el factor excluyente para determinar el placer en los clientes, en esta investigación se han identificado otros factores con igual o mayor relevancia. 
En ese sentido, el performance de las meretrices se erige como punto clave de las preferencias, seguido de cerca por el trato. Por otra parte, revisando solo las experiencias eufóricas, el aspecto físico cobra igual relevancia que el trato. Solo cuando se toman en cuenta las experiencias disfóricas es que el trato se convierte en factor determinante. En adición a ello, los esquemas tensivos demuestran que existen otras variables relevantes como el tiempo que duran los encuentros sexuales y la edad de las meretrices. Es así que la configuración de preferencias que determinan el placer/displacer de los usuarios se torna más complejo que el mero hecho de solo reducirlo a una variable exclusiva. Esta disparidad podría radicar en el diferente contexto geográfico en el que se enmarcan estas investigaciones. Mientras que Rocha, Liljeros y Holme (2010) y la de Holt y Belvins (2007) analizan páginas brasileñas y norteamericanas, respectivamente; este trabajo centra su foco de atención en un foro peruano. En otras palabras, las diferencias socioculturales podrían estar pesando en las preferencias de los clientes. Otro aspecto a considerar en cuanto a la variedad en los gustos y preferencias de los usuarios es el cumplimiento de una de las ventajas de las conexiones señaladas por Bauman (2006) pues, a diferencia de las relaciones, no están reñidas con la constante prueba y evaluación de diversos encuentros sexuales en busca del más satisfactorio.

El tercer y último punto abarcado en esta investigación responde al análisis de la plataforma como ente significativo. De esta manera, empleando el modelo sociosemiótico elaborado por Carlos Scolari se identificó dos propuestas de interacción: con los usuarios activos y con los pasivos. No obstante, el mayor énfasis recae en la interacción con los primeros al considerarlos más importantes que los segundos para la subsistencia del foro. Esto contraviene lo señalado por Casaló, Flavián y Guinalíu (2011) respecto a que los usuarios pasivos son igual de importantes que los activos para la comunidad virtual pues eventualmente le retribuirán lo que ésta les ha provisto. Empero, en ZonaCaleta no se observa ningún mecanismo de enganche ni interés por los usuarios que solo observan el contenido; solo a aquellos que comentan esporádicamente se les exhorta a colaborar con información antes que solicitarla. 
Por otra parte, a pesar que Sibilia (2008) plantea que las facultades provistas por los aplicativos digitales colaboran con el aumento de exposición de la vida privada, los resultados del análisis apuntan en otra dirección. A pesar de que se les provee de una serie de herramientas al momento de publicar sus posts (emoticones, elementos multimedia, avatars, etc), los usuarios de ZonaCaleta no suelen emplearlos con mucha frecuencia. Por el contrario, se limitan a la escritura cotidiana de textos para publicar sus experiencias sexuales. En ese sentido, estos aplicativos digitales solo se restringirían a lo señalado por Bauman (2006) respecto a que facilitan el acercamiento entre ganas y placer y el paso de un estado al otro, ya sea las ganas de encontrar información útil para luego satisfacer su líbido con un encuentro sexual, o las ganas de publicar un relato desaforado del coito con el placer posterior que les suscita que otros usuarios lo lean y lo celebren, o ambas. Al respecto, una investigación que ahonde en el perfil de este tipo de foristas podría hallar la respuesta a este y otro tipo de comportamientos.

Otro aspecto que es importante remarcar es el hecho de que se haya encontrado un alto índice de réplicas a los posts. Esto no solo indicaría que la comunidad virtual entiende que la interacción de sus miembros es vital para su subsistencia; sino que, como señala el trabajo de Rocha, Liljeros y Holme (2010), también comprenden que el intercambio de información es esencial para lograr el objetivo del foro: evitar potenciales estafas en el servicio de las prostitutas. Además, este tipo de interacción se enmarcaría en la nueva forma de socialización que existe en la red referida en el trabajo de Pérez (2012). Socialización que, como se ha visto, se encuentra regida por una serie de reglas (affordances) que, sino son obedecidas, devienen en consecuencias (breakdowns) para el usuario. Siguiendo esa línea, también sería importante para futuras investigaciones ahondar en uno de los espacios del foro donde la interacción es mucho más directa: el chat grupal (ver anexo 7).

En suma, los hallazgos de este trabajo, y sus coincidencias u contradicciones con otros, no han hecho sino describir algunas de las características del discurso de los usuarios del foro ZonaCaleta. A su vez, ello permite echar luces -de manera parcial- sobre las 
particularidades de las nuevas formas discursivas en torno a la sexualidad representada en soportes digitales.

\section{Referencias}

Ashford, C. (2008). Sex work in cyberpace: who pays de price? Information \& Communications Technology Law, 17(1), 37 - 49. Recuperado el 3 de Mayo de 2015, de http://myweb.dal.ca/mgoodyea/Documents/UK/Sex\%20work\%20in\%20cyb erspace $\% 20$ \%20who\%20pays \%20the\%20price\%20Ashford\%202008\%20Inf\%20Com\% 20Tech\%20Law\%2017\%281\%29\%2037-49.pdf

Baudrillard, J. (2000). Pantalla total. Barcelona: Anagrama.

Baudrillard, J. (2008). El éxtasis de la comunicación. En H. Foster, La posmodernidad (pp. 187 - 197). Barcelona: Editorial Kairós.

Bauman, Z. (2006). Amor líquido. Buenos Aires: Fondo de Cultura Económica.

Blevins, K., \& Holt, T. (2009). Examining the Virtual Subculture of Johns. Journal of Contemporary Ethnography, 38(5), 619 - 648. Recuperado el 16 de Junio de 2016, de http://news.msu.edu/media/documents/2009/10/e2b1e831-af47401f-a301-d22d74f10d9f.pdf

bloody_angel. (05 de Mayo de 2015). Re: URSULA - 999353840,flaquita timida [mensaje en un foro]. Recuperado de http://zonacaleta.com/foro/viewtopic.php?f=115\&t=30936\#p202081

Borda, L. (2006). La narración en foros de telenovelas como modo de afianzamiento comunitario. El caso de Betty La Fea en versión de sus fans. Revista 
Latinoamericana de Ciencias de la Comunicación, 3(4), 78 - 88. Recuperado el 5 de Mayo de 2015, de http://www.eca.usp.br/associa/alaic/revista/r4/art_06.pdf

Cáceres, M. D., Ruiz , J., \& Brändle, G. (2009). Comunicación interpersonal y vida cotidiana. La presentación de la identidad de los jóvenes en Internet. CIC, Cuadernos de Información y Comunicación, 14, 213 - 231. Recuperado el 13 de Junio de 2016, de http://revistas.ucm.es/index.php/CIYC/article/view/CIYC0909110213A/722 6

Casaló, L., Flavián, C., \& Guinalíu, M. (2011). Observación y participación activa en comunidades virtuales comerciales: el caso del sector turismo. Revista española de investigación de marketing ESIC, 15(2), 113 - 134. Recuperado el 12 de Junio de 2016, de http://www.esic.edu/documentos/revistas/reim/110905_095658_E.pdf

Chao-Min, C., Meng-Hsiang, H., \& Wang, E. (2006). Understanding knowledge sharing in virtual communities: an integration of social capital and social cognitive theories. Decision Support Systems, 42(3), 1872 - 1888. Recuperado el 15 de Junio de 2016, de https://www.researchgate.net/publication/222422090_Understanding_Knowl edge_Sharing_in_Virtual_Communities_An_Integration_of_Social_Capital_ and_Social_Cognitive_Theories

dany29_05. (02 de Agosto de 2015). Re: ROSA-PUENTE NUEVO-947806249 [mensaje en un foro]. Recuperado de http://zonacaleta.com/foro/viewtopic.php?f=19\&t=14530\#p206459

Fontanille, J. (2006). Semiótica del discurso. Lima: Fondo Editorial Universidad de Lima.

Fontanille, J., \& Zilberberg, C. (2004). Tensión y significación. Lima: Fondo de Desarrollo Editorial Universidad de Lima. 
Greimas, A. (1989). Del sentido II. Madrid: Editorial Gredos S.A.

Holt, T., \& Blevins, K. (2007). Examining sex work from the client's perspective: assessing johns using on-line data. Deviant Behavior, 28(4), 333 - 354. Recuperado el 15 de Junio de 2016, de http://www.centenary.edu/academics/religion/dotto/fye101/Holt\%20Blevins $\% 20$ article.pdf

Josmat271. (30 de Noviembre de 2015). Re: Irene - Huancayo [mensaje en un foro]. Recuperado de http://zonacaleta.com/foro/viewtopic.php?f=131\&t=35307\#p211087

Landowski, E. (1993). La sociedad figurada: Ensayos de sociosemiótica. México, D.F: Fondo de Cultura Económica.

Lipovetsky, G. (2000). La era del vacío. Barcelona: Anagrama.

loki. (15 de Setiembre de 2015). Re: Kasandra Room \#22 La de tetas al aire [mensaje en un foro]. Recuperado de http://zonacaleta.com/foro/viewtopic.php?f=9\&t=19083\&sid=4a8a45f5bcfe5 027d9b9d29348a80444\#p208405

Nasiri, A., Rostami, E., Bagher, M., \& Bakhshandeh, M. (2014). Discourse analysis of sex stories in a pornographic site in Iran. Scientific Journal of Pure and Applied Sciences, 3(7), 669 - 676. Recuperado el 17 de Junio de 2016, de http://sjournals.com/index.php/SJPAS/article/view/1552/pdf

oleroso. (26 de Agosto de 2015). Re: Oshin-Charapa [mensaje en un foro]. Recuperado de http://zonacaleta.com/foro/viewtopic.php?f=6\&t=34236\#p207458 
orgasmico. (19 de Setiembre de 2015). Re: SANDRA "La Tetuda" del Hs. Paraiso Pdro 1 de Huascar [mensaje en un foro]. Recuperado de http://zonacaleta.com/foro/viewtopic.php?f=19\&t=30381\#p188774

Perez, M. (2012). Identificaciones culturales en un foro de fans. Question. Revista Especializada en Periodismo y Comunicación, 1(35), 422 - 432. Recuperado el 6 de Mayot de 2015, de http://perio.unlp.edu.ar/ojs/index.php/question/article/view/1537/1379

Rocha, L., Liljeros, F., \& Holme, P. (2010). Information dynamics shape the sexual networks of Internet-mediated prostitution. Proceedings of the National Academy of Sciences, 107(13), 5706 - 5711. Recuperado el 17 de junio de 2016, de http://arxiv.org/ftp/arxiv/papers/1003/1003.3089.pdf

Sabater, C. (2014). La vida privada en la sociedad digital. La exposición pública de los jóvenes en Internet. Aposta: Revista de Ciencias Sociales, (61), Recuperado el 18 de Junio de 2016, de http://www.apostadigital.com/revistav3/hemeroteca/csabater.pdf

Scolari, C. (2004). Hacer clic. Hacia una sociosemiótica de las interacciones digitales. Barcelona: Editorial Gedisa S.A.

Sibilia, P. (2008). La intimidad como espectáculo. Buenos Aires: Fondo de Cultura Económica.

Siglanvir. (09 de Setiembre de 2015). Re: Briggite / San Miguel / 956802868

[mensaje en un foro]. Recuperado de

http://zonacaleta.com/foro/viewtopic.php?f=4\&t=34350\#p207924

Zizek, S. (2005). Bienvenidos al desierto de lo real . Madrid: Ediciones Akal. 


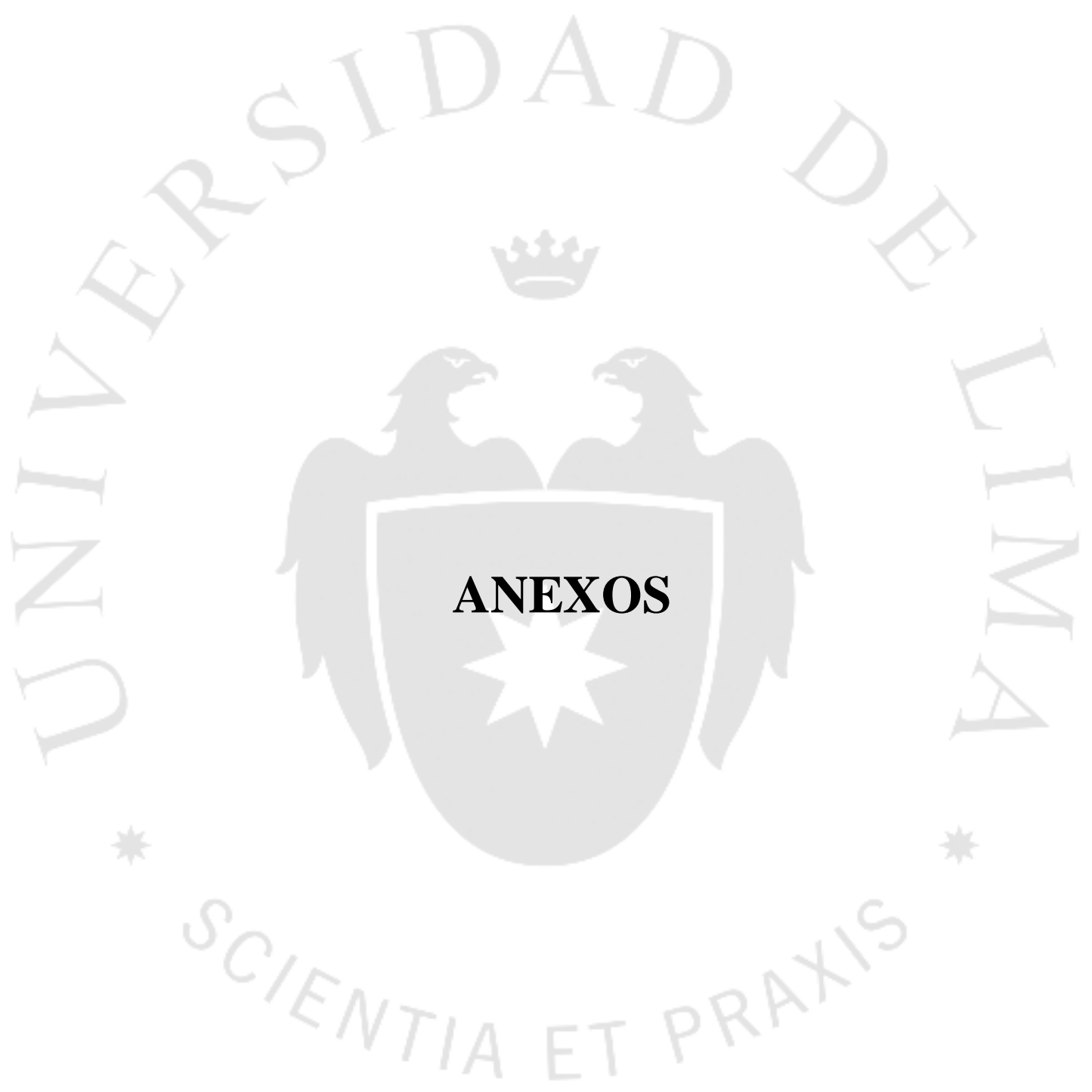




\section{ANEXO 1: Subsecciones del foro}

Apartados que dividen los posts según tema de discusión

\section{ECONOMICAS - CONO NORTE}

Chicas en Carabayllo, Ancón, Puente Piedra, San Martín de Porres, Santa Rosa, Comas, Independencia y Los

>) Olivos.

Moderadores: VENDEDOR, JuanCamaney, KOSAKO, Fox Mulder, shelotto

333517284 Último mensaje por ark07 0

temas mensajes Lun May 15, 2017 9:36 pm

SUbForo: O INDEPENDIENTES - CONO NORTE

ECONÓMICAS E INDEPENDIENTES - CONO ESTE

Chicas en Ate, Cieneguilla, Chaclacayo, El Agustino, Lurigancho (Chosica), San Juan de Lurigancho y Santa

Anita.

(1)

Moderadores: VENDEDOR, elpetimetre, JuanCamaney, MakO, KOSAKO, Fox Mulder

ECONÓMICAS E INDEPENDIENTES - CONO SUR

Chicas en Chorrillos, Lurín, Pachacamac, San Juan de Miraflores, Santa María del Mar, Villa El Salvador, Villa

$\checkmark$ María del Triunfo, Pucusana, Punta Hermosa, Punta Negra y San Bartolo.

Moderadores: VENDEDOR, elpetimetre, JuanCamaney, KOSAKO, Fox Mulder

ECONÓMICAS E INDEPENDIENTES - OTRAS ZONAS

Chicas en Breña, Jesús María, La Victoria, Lince, Magdalena del Mar, Pueblo Libre, Rimac, San Luis, San

Miguel, Surquillo y La Provincia Constitucional del Callao.

\begin{tabular}{l|l|l}
1769 & 8222 & Último mensaje por PapaOso 0
\end{tabular}

temas mensajes Mar May 16, 2017 1:10 pm

田

12775743 Último mensaje por kakanero o

temas mensajes Sab May 13, 2017 10:56 pm

(1)

14995764 Último mensaje por elmajoxa9 0

temas mensajes Jue May 11,2017 9:00 pm

(1)

ECONÓMICAS E INDEPENDIENTES - LIMA CENTRO

Chicas independientes en Lima centro y Chicas de esquina.

Moderadores: VENDEDOR, elpetimetre, JuanCamaney, MakO, KOSAKO, Fox Mulder

SUbforo: OCHICAS DE ESQUTNA

\section{ZONAS DE RELAXY CHICAS EN EL INTERIOR DEL PAIS}

PROSTIBULOS, NIGHT CLUBS E INDEPENDIENTES - NORTE PERUANO

Chicas en Tumbes, Piura, Cajamarca, Lambayeque, La Libertad y Ancash.

> Incluye zona norte de Lima.

Moderadores: EL VERTDICO, VENDEDOR, KOSAKO

SUbforos: O ANCASH, O CAJAMARCA, O LAMBAYEOUE, O LA LIBERTAD, O PIURA 


\section{ANEXO 2: Normas del foro}

\section{Algunas de las normas de conducta establecidas para los usuarios del foro}

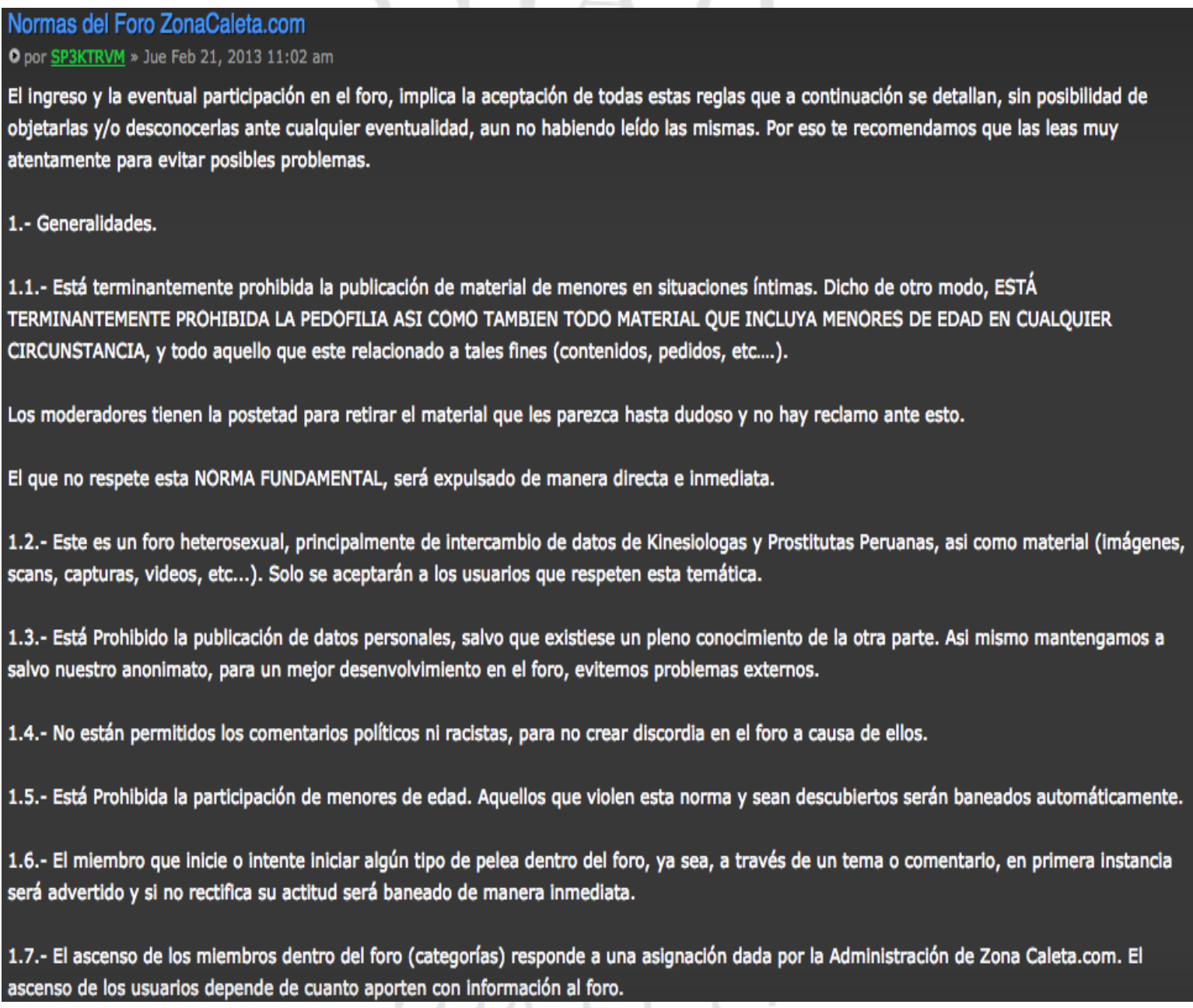




\section{ANEXO 3: Plantilla de calificación}

Plantilla con las variables que emplean los usuarios para calificar a las meretrices

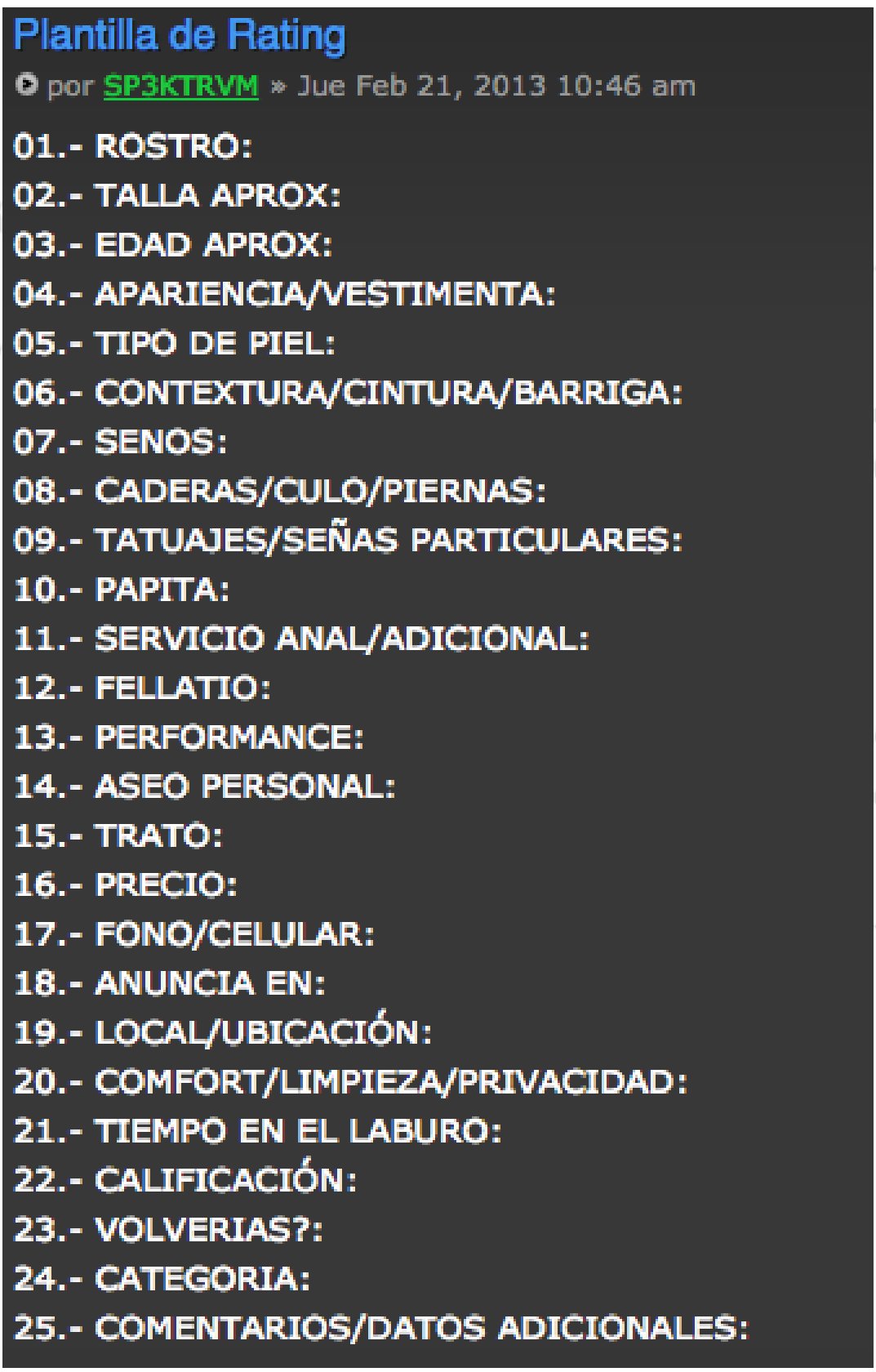




\section{ANEXO 4: Aviso de advertencia}

Ejemplo de aviso de advertencia del moderador ante infracción de conducta de un usuario

[code][code] :dog: :dog: :dog: Solo doy me peercepsion de la flaca, no es par que elimines mis comentarios, por el hecho que es moderador[/code][/code]

¿ voy a eliminar todo lo que no sea un rating, el foro se nutre de ratings no de tu "percepcion".

obviamente ya con esta advertencia recibida, espero que lo siguiente que postees sea un rating. 0 simplemente te bajare el dedo y te baneare de inmediato.

Buscamos gente que aporte datos consistentes, no huevadas.

Gracias.

Kosako 


\section{ANEXO 5: Réplica directa}

Ejemplo de réplica directa a un post de calificación

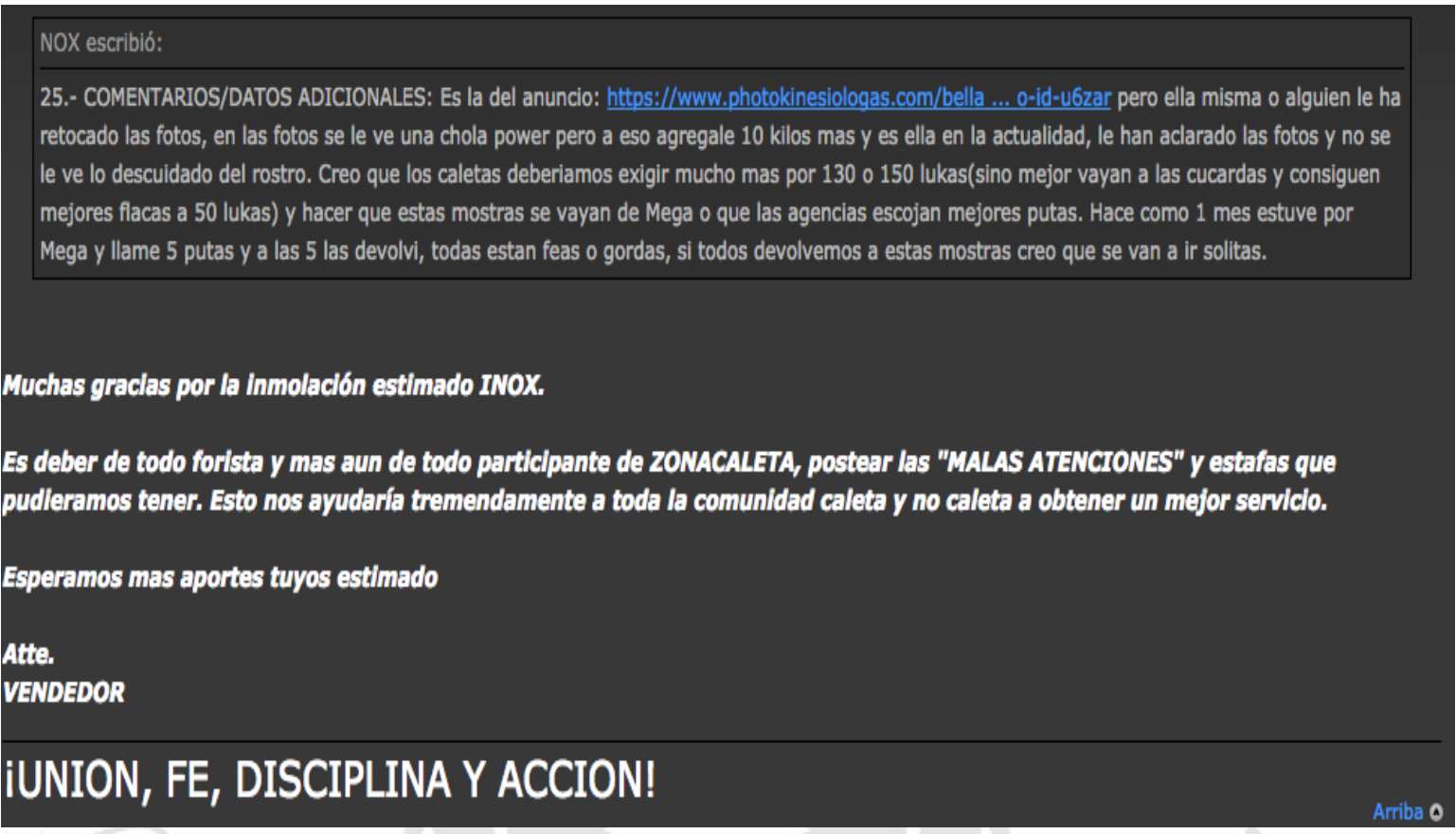




\section{ANEXO 6: Niveles de jerarquía}

El moderador es el nivel más alto que puede alcanzar un usuario en la jerarquía del foro

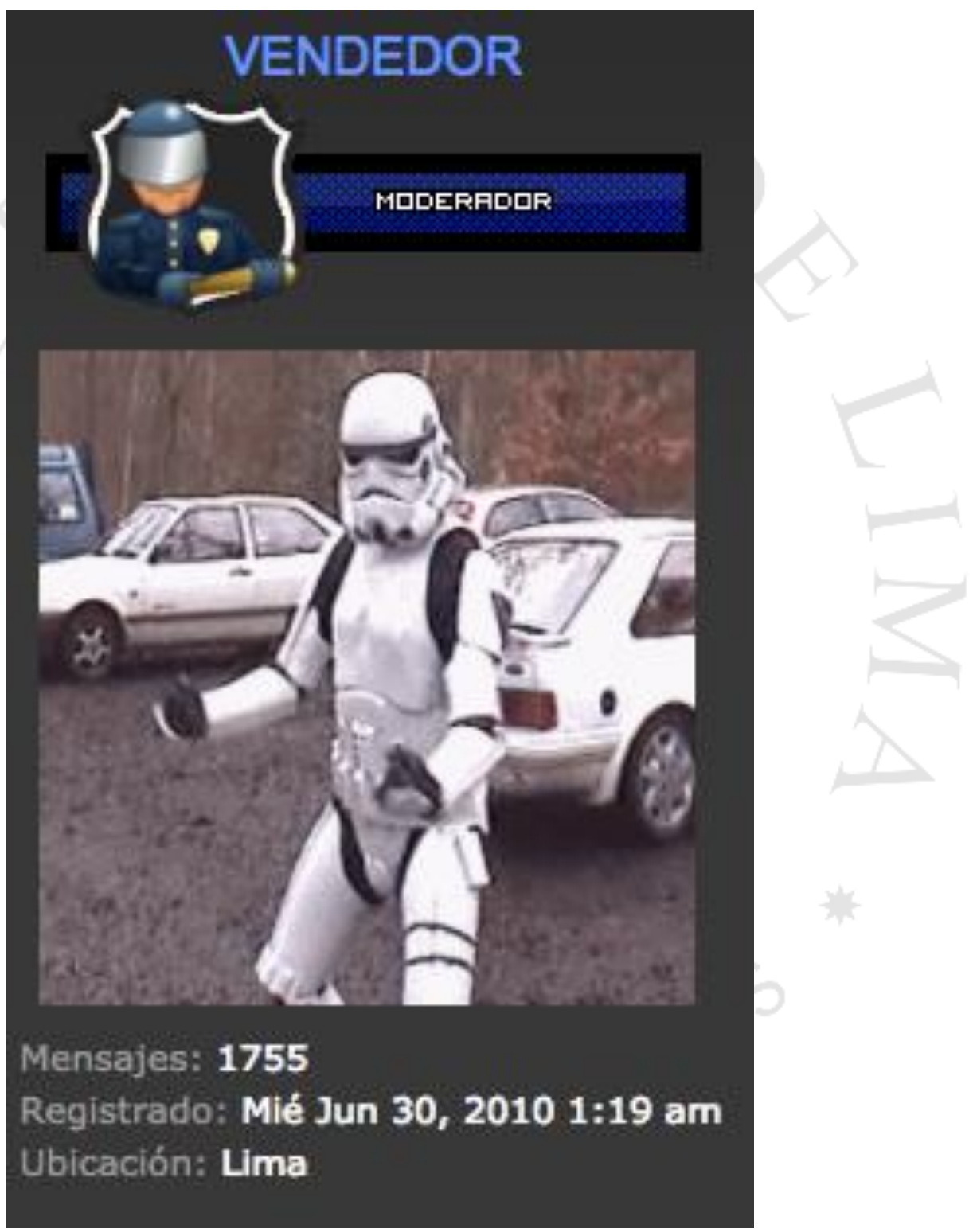




\section{ANEXO 7: Chat grupal}

Ejemplo de conversación entre usuarios en el chat del foro

\begin{tabular}{|l|l|l|}
\hline Cazakine12: ALGUIEN DE SJL 1M,ETRO & Mar May 2 4:36:12 PM \\
\hline$?$ & Cazakine12: ALGUIEN DE SJL 1 METRO & Mar May 2 5:18:32 PM \\
\hline TXSlow: gente, alguien que conozca una flaca sumisa que le interese el sadomasoquismo? o alguien conoce un foro para intercambiar \\
\hline material de ese tipo?
\end{tabular}

